This item was submitted to Loughborough's Research Repository by the author.

Items in Figshare are protected by copyright, with all rights reserved, unless otherwise indicated.

\title{
Characterisation of microstructure and creep properties of alloy 617 for high- temperature applications
}

\section{PLEASE CITE THE PUBLISHED VERSION}

https://doi.org/10.1016/j.msea.2014.09.046

\section{PUBLISHER}

(C) Elsevier

VERSION

AM (Accepted Manuscript)

\section{PUBLISHER STATEMENT}

This work is made available according to the conditions of the Creative Commons Attribution-NonCommercialNoDerivatives 4.0 International (CC BY-NC-ND 4.0) licence. Full details of this licence are available at: https://creativecommons.org/licenses/by-nc-nd/4.0/

\section{LICENCE}

CC BY-NC-ND 4.0

\section{REPOSITORY RECORD}

Di Martino, Fabio, Roy G. Faulkner, Simon Hogg, S. Vujic, and O. Tassa. 2014. "Characterisation of Microstructure and Creep Properties of Alloy 617 for High-temperature Applications". Loughborough University. https://hdl.handle.net/2134/26488. 


\title{
Characterisation of Microstructure and Creep Properties of Alloy 617 for High-Temperature Applications
}

\author{
S.F. Di Martino ${ }^{\dagger} *$, R.G. Faulkner*, S.C. Hogg*, S. Vujic ${ }^{*}$, O. Tassa ${ }^{+}$ \\ † Corresponding author, Tel. +44 01509 263171, Ext.: 4361; e-mail \\ S.F.Di-Martino@lboro.ac.uk \\ * Department of Materials, Loughborough University, LE11 3TU, UK \\ $\neg$ Institute for Materials Science and Welding, Kopernikusgasse 24, 8010 Graz \\ Austria \\ + Centro Sviluppo Materiali, Via di Castel Romano 100-102, 00128 Castel \\ Romano, Italy
}

\begin{abstract}
Current energy drivers are pushing research in power generation materials towards improved efficiency and improved environmental impact. In the context of new generation ultra-supercritical (USC) power plant, this is represented by increased efficiency, service temperature reaching $750^{\circ} \mathrm{C}$, pressures in the range of 35 - 37.5 MPa and associated carbon capture technology. Ni base alloys are primary candidate materials for long term high temperature applications such as boilers. The transition from their current applications, which have required lower exposure times and milder corrosive environments, requires the investigation of their microstructural evolution as a function of thermo-mechanical treatment and simulated service conditions, coupled with modelling activities that are able to forecast such microstructural changes. The lack of widespread microstructural data in this context for most nickel base alloys makes this type of investigation necessary and novel. Alloy INCONEL 617 is one of the Ni-base candidate materials. The microstructures of four specimens of this material crept at temperatures in the $650^{\circ} \mathrm{C}-750^{\circ} \mathrm{C}$ range for up to $20000 \mathrm{~h}$ have been characterised and quantified. Grain structure, precipitate type and location, precipitate volume fraction, size and inter-particle spacing have been determined. The data obtained are used both as input for and validation of a microstructurally-based CDM model for forecasting creep properties.
\end{abstract}

Keywords: INCONEL 617, Ni-base alloys, ultra-supercritical power plant, microstructural evolution, creep, modelling 


\section{INTRODUCTION}

The material requirements for USC applications, operating with steam target temperatures as high as $750^{\circ} \mathrm{C}$ and pressures of $35-37.5 \mathrm{MPa}$, have brought forward the need for adapting and further developing existing materials, such as Ni-base superalloys. These have been used to date in relatively short term applications such as turbine engines in the aerospace industry. Forecasted requirements for USC applications have set the targets at minimum creep strength of $100 \mathrm{MPa}$ at $100000 \mathrm{~h}$ of service [1-7]. Since the microstructure of most of the candidate nickel base alloys has not been investigated after such long exposure periods of time, modelling activity has proven to be helpful in predicting the material microstructural response under simulated service conditions [8]. The superior combination of high temperature strength, corrosion/oxidation resistance and creep resistance make alloy INCONEL 617 (referred to as alloy 617) one of the Ni-base candidate materials. Alloy 617 is defined as a solid-solution strengthened material which is generally put in service in the solution annealed condition. However, the presence of $\gamma^{\prime}$ and carbides, such as $\mathrm{M}_{23} \mathrm{C}_{6}, \mathrm{M}_{6} \mathrm{C}$ and $\mathrm{MX}$ in the as-received and in the aged conditions, plays a significant role in hardening the material [9-12] The present investigation concentrates on linking microstructural evolution of alloy 617 as a function of different thermo-mechanical treatments to the modelling activity, which forecasts creep behaviour, and comparing the predictions with experimental data. The microstructural analysis provides characterisation of the microstructural constituents and the quantification of phase fractions, mean particle size and inter-particle spacing (IPS). The quantitative data obtained serve as input and validation for the model predictions. The model combines a continuum damage mechanics (CDM) approach which has been successfully used for the prediction of creep rupture properties of $9 \mathrm{wt} \%$-Cr ferritic steel [13], and which is now being adapted to the case of Ni-base superalloys systems.

\section{EXPERIMENTAL PROCEDURE}

\subsection{Materials}

The nominal chemical composition of the alloy studied in this investigation is listed in table 1. 
Table 1: Composition of IN617

\begin{tabular}{|c|c|c|c|c|c|c|c|c|c|c|c|c|c|}
\hline \multirow[t]{2}{*}{ Alloy } & \multicolumn{12}{|c|}{ Chemical composition weight \% } & \\
\hline & $C$ & Mn & Si & Al & $\mathrm{Cr}$ & $C u$ & Co & Mo & $F e$ & Ti & $N b+T a$ & $B$ & $\mathrm{Ni}$ \\
\hline \multirow{2}{*}{ IN617 } & 0.05 & -- & -- & 0.08 & 20.0 & -- & 10.0 & 8.0 & -- & -- & -- & -- & Bal \\
\hline & 0.15 & 1.0 & 1.0 & 1.5 & 24.0 & 0.05 & 15.0 & 10.0 & 3.0 & 0.6 & -- & 0.06 & $\mathrm{Bal}$ \\
\hline
\end{tabular}

The 617 samples were investigated in the solubilised as-received (AR) and in the crept condition. The creep tests were not conducted to rupture. For phase quantification and modelling purposes, a fifth 617 specimen aged over a short period of time was also investigated. Table 2 summarises the thermo-mechanical treatment that the various specimens underwent before investigation.

Table 2: Sample specifications

\begin{tabular}{|c|c|c|c|}
\hline Specimen & $\begin{array}{c}\text { Temperature } \\
\left({ }^{\circ} \mathbf{C}\right)\end{array}$ & Load (MPa) & Time (h) \\
\hline AR & - & - & - \\
\hline 1 & 650 & 130 & 19299 \\
\hline 2 & 700 & 110 & 20764 \\
\hline 3 & 700 & 94 & 20168 \\
\hline 4 & 750 & 68 & 16075 \\
\hline 5 & 750 & - & 100 \\
\hline
\end{tabular}

\subsection{Investigation Procedure}

Cutting of the samples was carried out using a Struers Accutom-5 cutting machine. Bakelite mounting for all samples was carried out in a Struers ProntoPress-10 machine. A Struers TegraPol-25 automatic polishing machine was used for both grinding and polishing. The latter was carried out with a $6 \mu \mathrm{m}$ and finally $1 \mu \mathrm{m}$ particle size diamond solution. Colloidal silica polishing was carried out for electron back-scatter diffraction (EBSD) analysis. Acetic glyceregia (a mixture of acetic acid, glycerine, $\mathrm{HCl}$ and $\mathrm{HNO}_{3}$ ) was used as etching reagent for preparing 617 samples to reveal the microstructural features. A LEO 1530VP field emission gun scanning electron microscope (FEG-SEM) was used to image the sample surfaces. The most useful detection mode for this analysis was high resolution secondary electron referred to as In-lens. Energy dispersive X-ray analysis (EDX) was performed in the FEG-SEM system using an Oxford Instruments X-Max $80 \mathrm{~mm}^{2}$ detector. Elemental mapping and point 
spectra were obtained for all the samples. EBSD analysis provided grain size and morphology. The system uses HKLNordlys F high speed Camera and Oxford Instrument Aztec EDX/EBSD microanalysis software for data collection. The grain size was also confirmed by using the mean linear intercept method. The hardness of all samples was measured by means of an Innovatest Nexus Series machine. A $10 \mathrm{~kg}$ load and $15 \mathrm{~s}$ dwell time were applied. For each sample, ten measurements were performed and the average hardness value determined. Finally, thermodynamic and kinetic calculations have been carried out with the thermo-kinetic software MatCalc (version 5.52) including the nickel thermodynamic database (version 2.00 prebeta 016 ) and diffusion database (version 2.00 prebeta 001.

\subsection{Phase quantification, particle size and inter-particle spacing (IPS) analyses}

In order to obtain statistically meaningful results, the phase quantification was performed on large areas imaged by means of FEG-SEM (In-lens). In order to validate the use of this technique, comparison was made with images obtained by means of TEM performed on samples obtained from another Ni-base alloy, nominally IN740 (Ni-0.03C-0.3Mn-0.5Si-0.9Al-25Cr-20Co-0.5Mo-0.7Fe-1.8Ti$2 \mathrm{Nb}+\mathrm{Ta}$ ) [14] as part of a similar phase quantification exercise. Montages of individual high magnification images were produced so that large areas could be analysed while retaining the ability of quantifying fine phases. Carbon replica were extracted for the large particles, such as $M X$ and $\mathrm{M}_{23} \mathrm{C}_{6}$, whilst thin foils were produced specifically for the analysis of the $\gamma^{\prime}$ particles. The morphology and dimension of the particles were comparable and therefore the FEGSEM imaging has been adopted as the main technique for phase imaging and quantification, the main advantages being the relative ease of sample preparation and the possibility of analysing very large areas, impossible to accomplish by using TEM. Figure 1 shows $M X$ and $\mathrm{M}_{23} \mathrm{C}_{6}$ particles imaged using TEM (1a) and FEGSEM (1b), precipitated at a grain boundary, having comparable dimensions. 

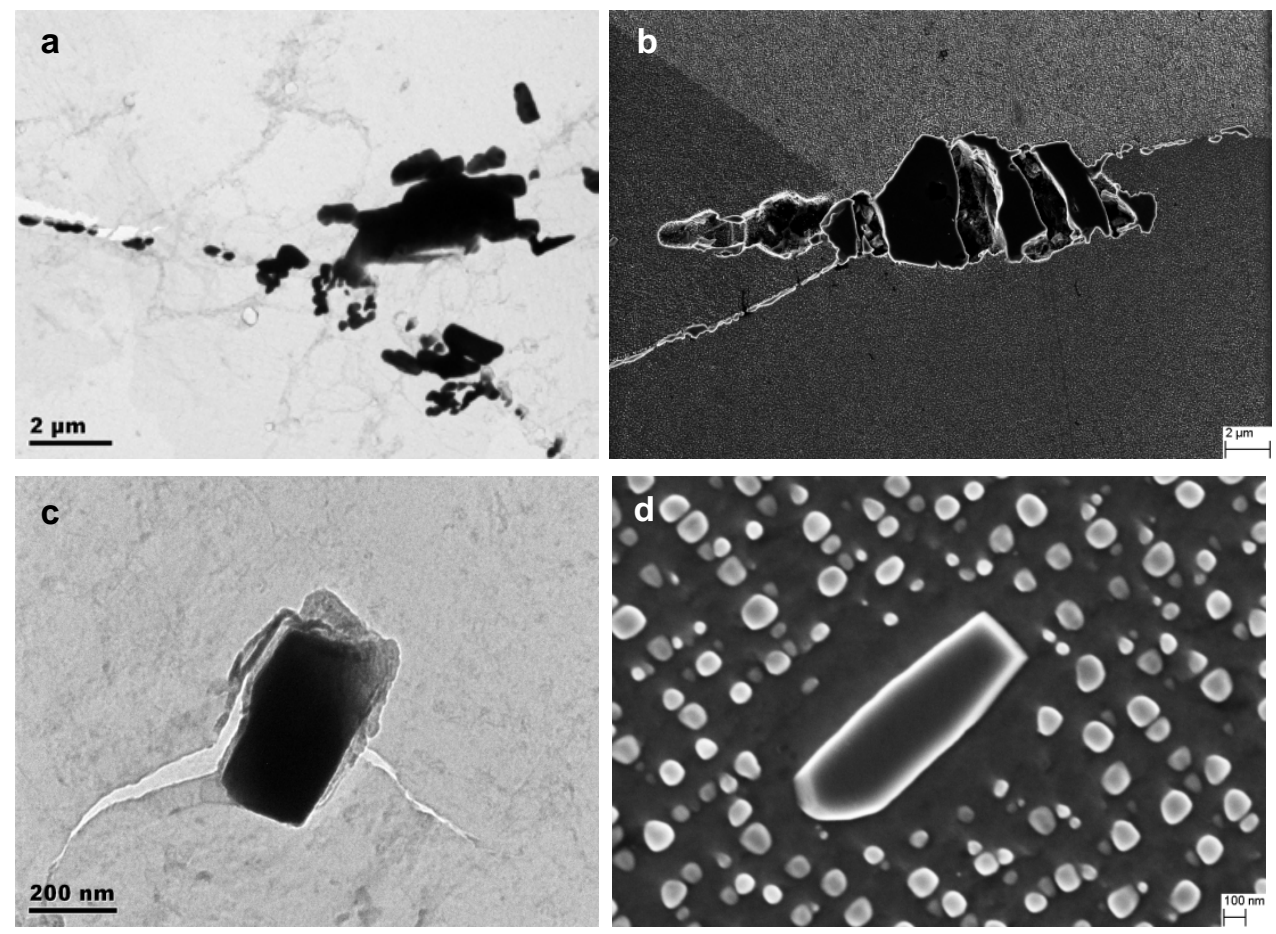

Figure 1: comparison between particles imaged by means of TEM on replica (left) and FEGSEM (right)

Figure 2 shows the reproducibility of $\gamma$ ' particle size and dimensions, when they are imaged by means of TEM (2a) and FEGSEM (2b). Beside the many advantages of performing the quantification of $\gamma^{\prime}$ by means of FEGSEM, there are associated inherent inaccuracies in the measurements.
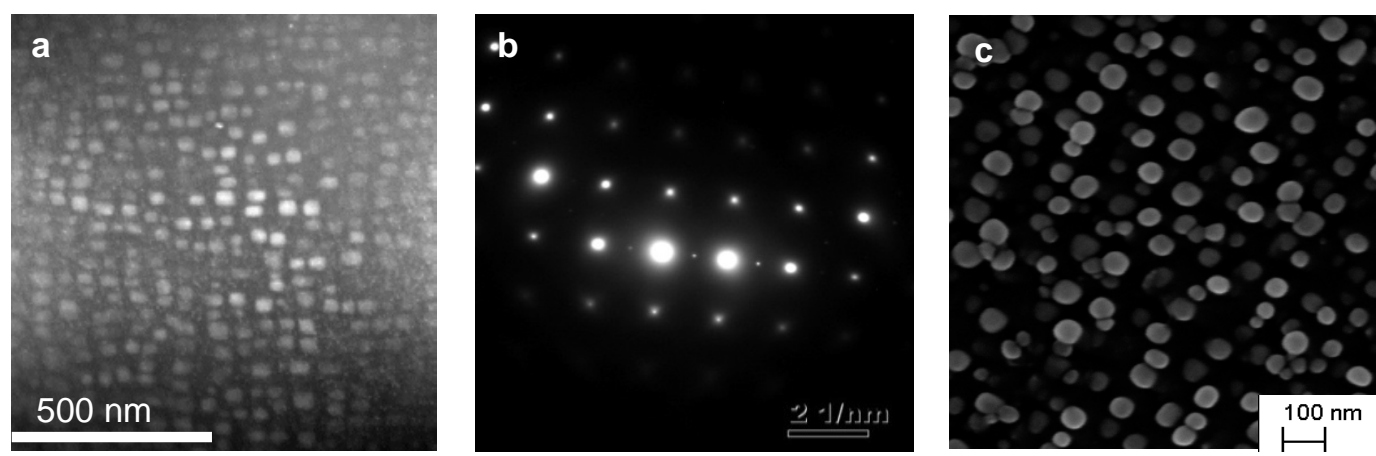

Figure 2: comparison between $\gamma$ ' particles imaged by means of dark field TEM on thin foil (a) and FEGSEM (c); diffraction pattern showing super-lattice reflections of the $\gamma$ ' particles is also shown (b) 
The main source of error derives from the orientation of the precipitates which, when imaged in two dimensions, provide different results depending on what section of the precipitates is observed and measured. In this study the method consistently followed is based on three specific conditions:

- A large number of particles belonging to different sample areas are measured

- The particles considered fall within the same threshold of contrast allowed by the In-lens detection mode, which suggests which regions of the particles close to the same plane of observation

- In the case of cuboids, the areas of interest are chosen so that the sides of the particles are as parallel as possible to the observed plane

The results obtained following this method have been compared to results obtained by means of TEM examination and with thermodynamic and kinetics calculations predicting the expected $\gamma^{\prime}$ volume fractions as a function of isothermal exposure. The results obtained have proven to fit well with both TEM measurements and modelling predictions.

The tables in this article present results obtained by separately quantifying: all particles excluding $\gamma^{\prime} ; \gamma^{\prime}$ particles; intergranular (GB) particles. The main reason for carrying out distinct analysis on different types of particles is mainly due to the average size of the particles. GB particles and $\gamma^{\prime}$ particles are usually finer than the larger MX particles and require higher magnification imaging. Finally, grain boundaries considered for the analysis have been assumed to be representative for the majority of the microstructure. Figure 3a shows a schematic of image processing carried out for the assessment of area fraction, particle size and IPS in the case of GB particles. The IPS is calculated following two different procedures and comparing the results. One is performed by considering the distance between two neighbouring particles along the grain boundary (see Figure 3b). Another one is performed by considering the portion of precipitate lying along the GB (usually coinciding with the major axis of the particle's equivalent ellipse, as shown in Figure 3a), the total number of particles and the total GB length considered, and subsequently deriving the IPS value using standard stereography techniques. The GBs analysed are considered statistically representative of any other possible two-dimensional section randomly chosen. This results in the minimization of measurement errors arising from stereography. Finally, Figure 3c shows a schematic of image processing carried out for the assessment of area fraction of $\gamma^{\prime}$ particles. 

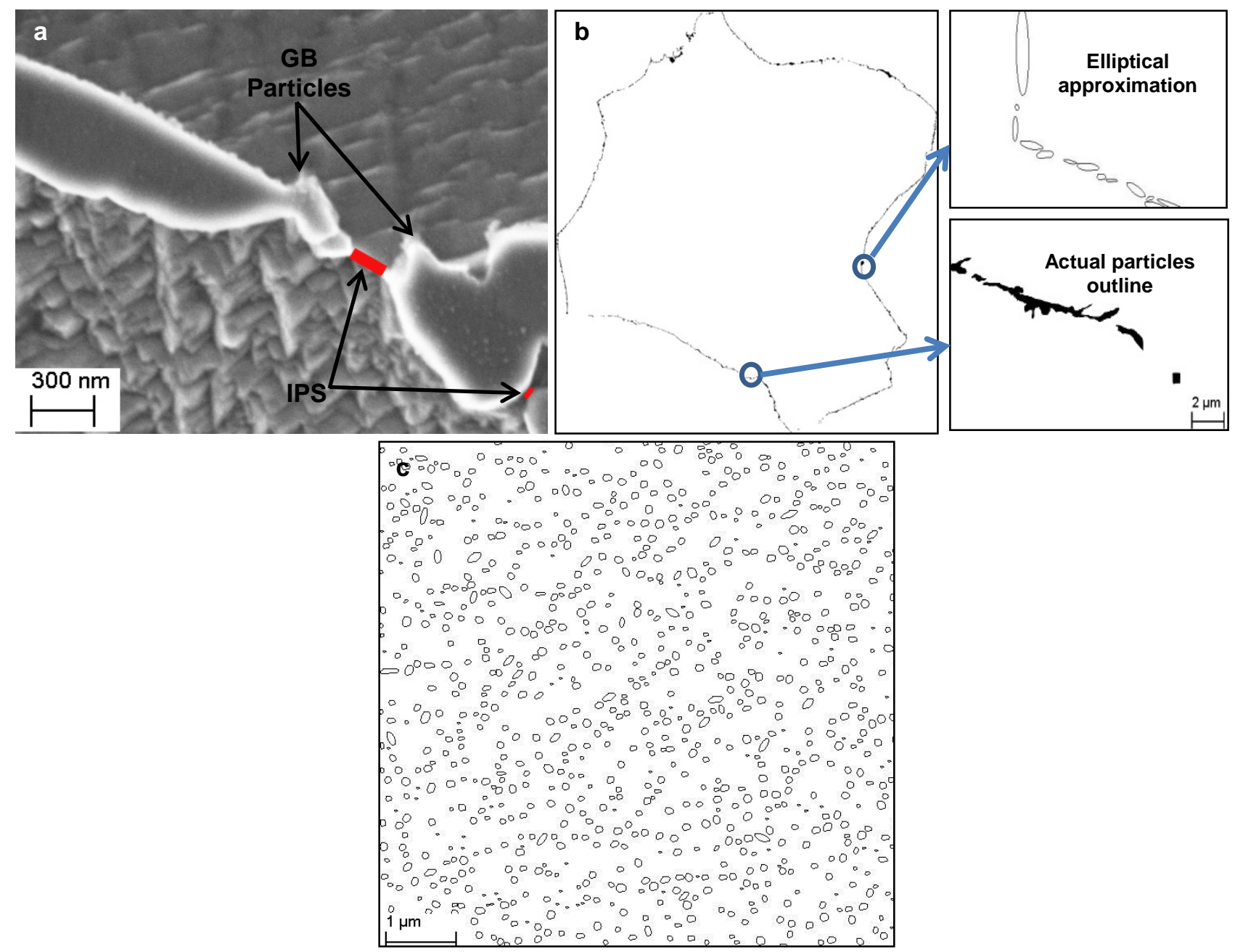

Figure 3: a) example of manual measurements of IPS for grain boundary particles; b) Schematic of GB and close up on a particular region of outlined precipitates and on another one where elliptical approximation has been performed; c) Schematic of $\gamma^{\prime}$ particles outlines on which area fraction, size and IPS analysis are performed

The nature of the predictive creep model discussed in the following section does not require the exact species of the precipitates, as long as their hardening contribution is known [15]. In this case the precipitates have all been considered as having a positive hardening contribution, assuming that their hardness is sufficient to result in dislocation bypass rather than cutting. 


\section{RESULTS AND DISCUSSION}

\subsection{Microstructural analysis of alloy IN617 crept specimens}

The grain size and morphology remained stable throughout the creep tests in all the specimens. Visible grain degeneration or cavitation was not found in any of the samples due to the creep test. Figure 4 shows an inverse pole figure (IPF) map of the as-received (AR) sample, produced by using EBSD, which can be considered representative of all the grain structures observed in the crept specimens. The calculated average grain sizes for each specimen are summarised in Table 3. The $\Sigma 3$ twin boundaries have not been included when determining the grain size. Hardness testing was also performed on the four crept samples and the average hardness is shown in Table 4.

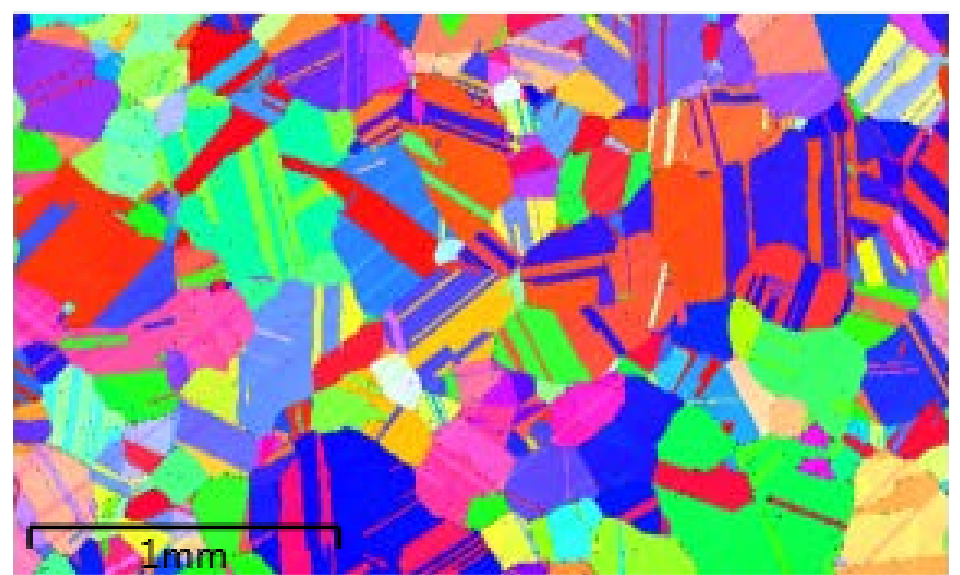

Figure 4: Inverse pole figure (IPF) map showing the grain structure and orientation in the as-received alloy 617 sample

Table 3: Average grain size for the IN617 AR and crept specimens

\begin{tabular}{|c|c|c|c|c|}
\hline \multicolumn{5}{|c|}{ Average grain size $(\boldsymbol{\mu m})$} \\
\hline $\begin{array}{c}\text { sample } \\
\text { AR }\end{array}$ & sample 1 & sample 2 & sample 3 & sample 4 \\
\hline $156 \pm 36$ & $137 \pm 38$ & $123 \pm 31$ & $176 \pm 29$ & $148 \pm 28$ \\
\hline
\end{tabular}

Table 4: Average hardness for the four IN617 crept samples

\begin{tabular}{|l|c|c|c|}
\hline \multicolumn{4}{|c|}{ Hardness (HV) } \\
\hline sample 1 & sample 2 & sample 3 & sample 4 \\
\hline $365 \pm 18$ & $322 \pm 23$ & $343 \pm 19$ & $331 \pm 21$ \\
\hline
\end{tabular}


Besides revealing the grain structure of the AR sample, the etching process had the effect of causing precipitates in the microstructure to detach, as shown in Figures 5 and 6, nonetheless making very visible the impressions of the particles that were formerly present. The morphology, dimensions and location are helpful in trying to identify the species of precipitates present in the AR sample. Two kinds of precipitate were observed: these are MX and $\mathrm{M}_{23} \mathrm{C}_{6}$. Ti enrichment in MX type precipitates provides dark contrast. This information coupled with the geometrically regular morphology of the precipitate suggests that the nature of such particles is TiN. Figure 6, showing an elemental map obtained by means of EDX analysis, and Figure 7, showing selected point spectra, confirm that all the other globular-shape precipitates are $\mathrm{Cr}$ and Mo rich $\mathrm{M}_{23} \mathrm{C}_{6}$ carbides. From the similar morphology of the impressions, it is probable that all the precipitates that detached during etching are $\mathrm{M}_{23} \mathrm{C}_{6}$ type carbides.
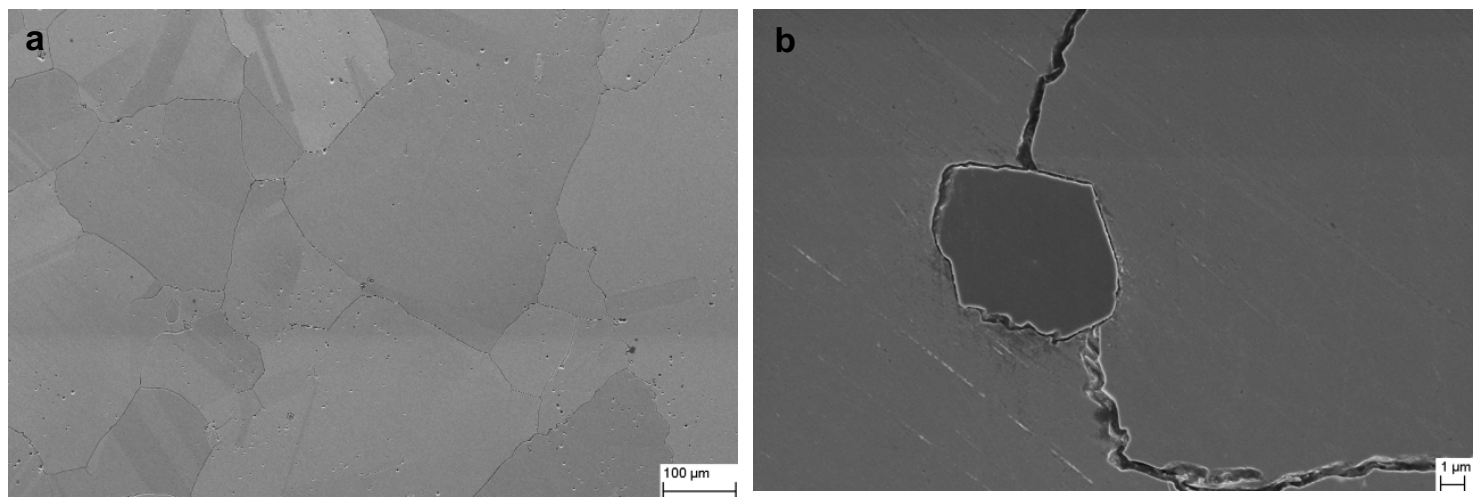

Figure 5: (a) low magnification image of IN617 AR sample; (b) MX at grain boundary site 

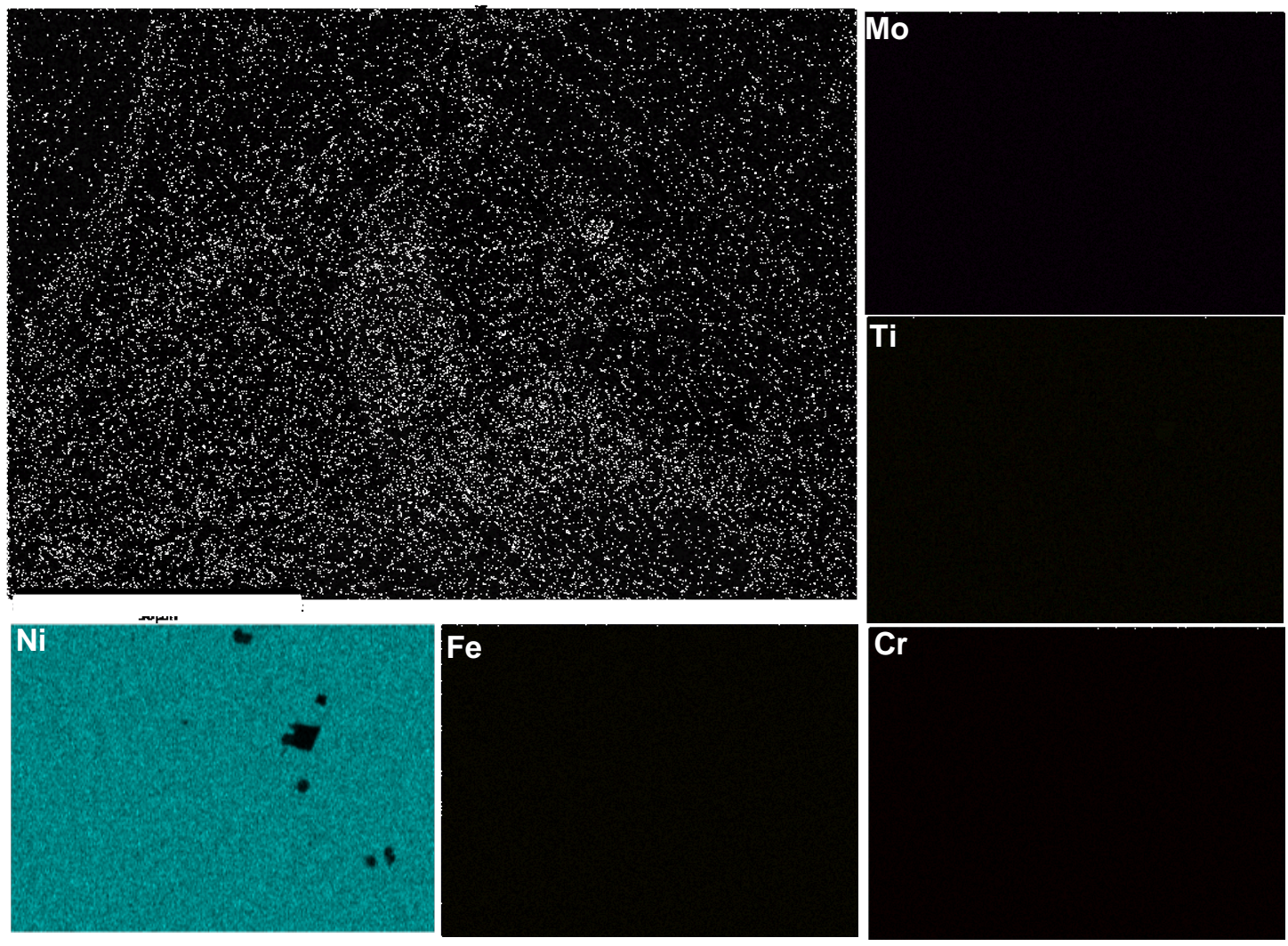

Figure 6: EDX map of as-received alloy IN617
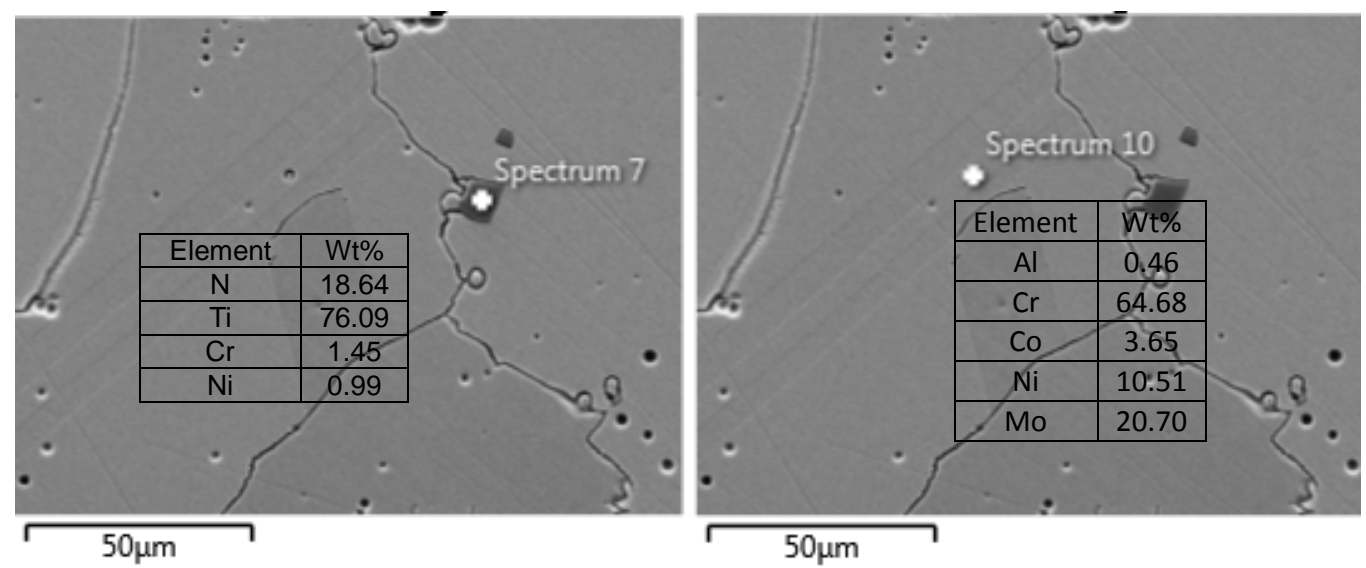

Figure 7: Chemical analysis of two different precipitates being TiN (left) and $M_{23} C_{6}$ (right) 
The high temperature exposure causes the as-received microstructure to evolve [9-12, 16-22]. With the exception of $\mu$ phase, which only precipitates in the samples exposed at temperatures equal or higher than $700^{\circ} \mathrm{C}, \mathrm{MX}, \mathrm{M}_{23} \mathrm{C}_{6}$, $\mathrm{M}_{6} \mathrm{C}$ and $\gamma^{\prime}$ are encountered in all the crept samples. The volume fraction and particle size differ from sample to sample, according to the thermodynamic and kinetics conditions determined by the thermo-mechanical treatment. As a representative result, Figure 8 shows the chemical analysis of a region of sample 3 which contains all the phases of interest. The $\gamma^{\prime}$ particles are too fine to be distinguished at this magnification, whilst all the other phases can be identified through both chemical and contrast information. Mo-rich $\mu$ phase (providing bright contrast when imaged by means of In-lens and SE2 detection mode) is found to be present and mixed with $\mathrm{M}_{6} \mathrm{C}$ (Mo-rich particles providing intermediate contrast when imaged by means of In-lens and SE2 detection mode), Cr-rich $\mathrm{M}_{23} \mathrm{C}_{6}$, and Ti-rich $\mathrm{MX}$.
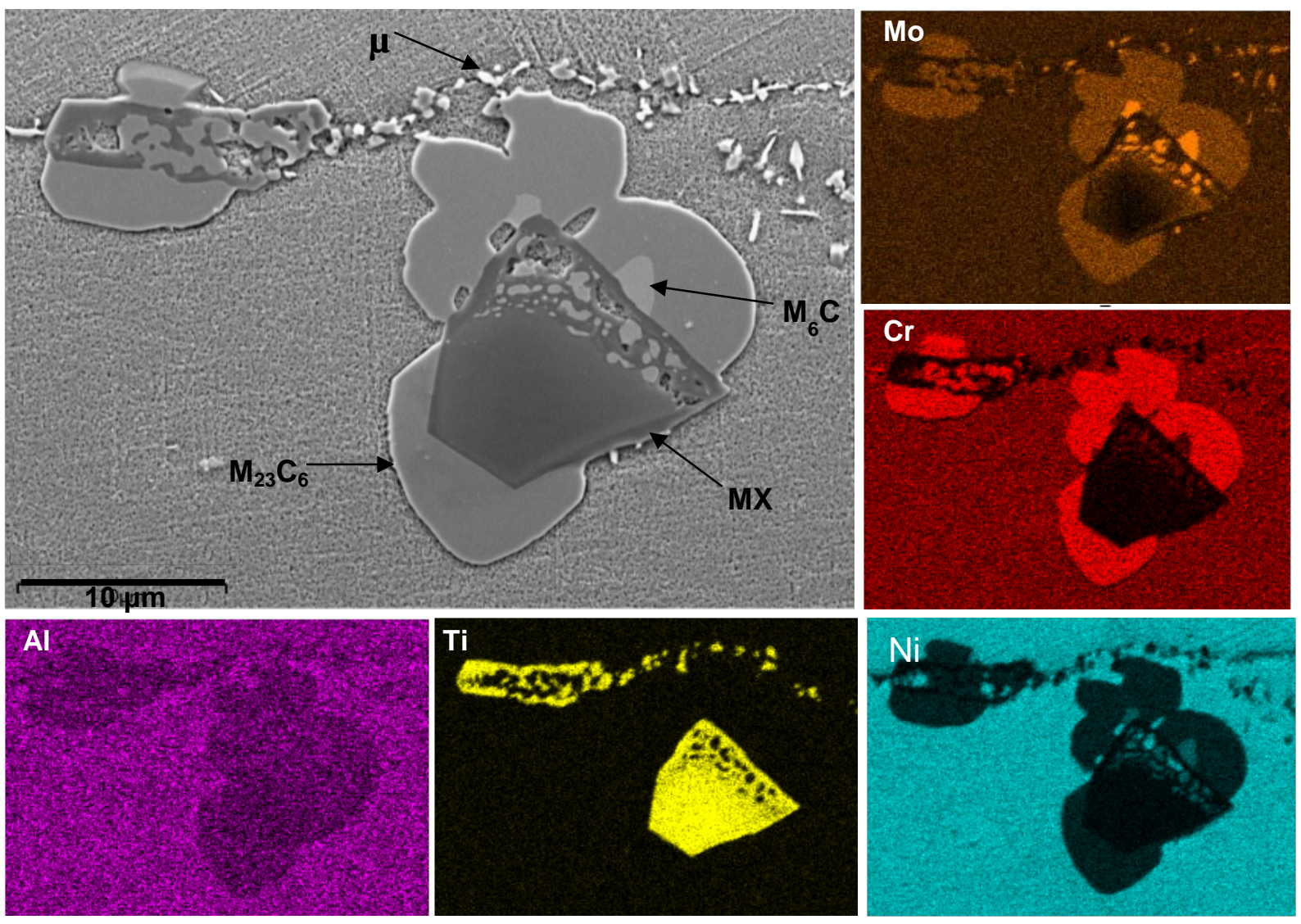
Figure 8: EDX mapping analysis carried out on sample 3 where $\mu$ phase (bright contrast) is mixed with $M_{6} C$ (Mo-rich with intermediate contrast), Cr-rich $M_{23} C_{6}$ and Ti-rich $M X$

The microstructures of the four crept samples, therefore, show common features. The phases observed after long term high temperature exposure are summarised in Table 5. Figure 9 shows selected examples of the microstructural constituents' morphology in the crept samples.

\section{Table 5: Summary of phases present in IN617 crept samples}

\begin{tabular}{|c|c|c|c|}
\hline Precipitate & Location & Morphology & Remarks \\
\hline$\gamma^{\prime}$ & Intragranular & Spheroidal & $\begin{array}{l}\text { The long term heat exposure } \\
\text { promoted the precipitation of } \\
\gamma \text { ' phase. Certain areas of } \gamma \\
\text { was observed transformed } \\
\text { from MX precipitates. }\end{array}$ \\
\hline MX & $\begin{array}{c}\text { Intragranular } \\
\text { GBs }\end{array}$ & $\begin{array}{l}\text { Globular } \\
\text { Blocky } \\
\text { Regular }\end{array}$ & $\begin{array}{l}\text { MX precipitates have a } \\
\text { random distribution. Nitrides } \\
\text { were observed to have a } \\
\text { geometrically regular shape. }\end{array}$ \\
\hline $\mathrm{M}_{23} \mathrm{C}_{6}$ & $\begin{array}{c}\text { GBs } \\
\text { Twin boundaries } \\
\text { Nucleated on } \\
\text { MX }\end{array}$ & $\begin{array}{l}\text { Globual } \\
\text { Celluar } \\
\text { Irregular }\end{array}$ & $\begin{array}{l}\text { Grain boundaries as well as } \\
\text { twin boundaries were } \\
\text { observed decorated with a } \\
\text { large amount of } \mathrm{M}_{23} \mathrm{C}_{6} \\
\text { carbides. Precipitate } \\
\text { coarsening was observed. }\end{array}$ \\
\hline $\mathrm{M}_{6} \mathrm{C}$ & $\begin{array}{l}\text { Intragranular } \\
\text { GBs } \\
\text { Nucleated on } \\
\text { MX }\end{array}$ & $\begin{array}{l}\text { Globular } \\
\text { Celluar } \\
\text { Blocky }\end{array}$ & $\begin{array}{l}\text { Present in the microstructure } \\
\text { mixed with } M_{23} C_{6} \text { and } M X \text {. }\end{array}$ \\
\hline$\mu$ & $\begin{array}{c}\text { GBs } \\
\text { intragranular }\end{array}$ & $\begin{array}{l}\text { Irregular } \\
\text { Platelets }\end{array}$ & $\begin{array}{l}\text { Observed after high } \\
\text { temperature exposure both } \\
\text { intragranularly and at GBs. } \\
\text { Partially mixed with } \mathrm{M}_{23} \mathrm{C}_{6} \text {. } \\
\text { Not observed in sample } 1 \text {, i.e. } \\
\text { at temperatures below } 700^{\circ} \mathrm{C}\end{array}$ \\
\hline
\end{tabular}



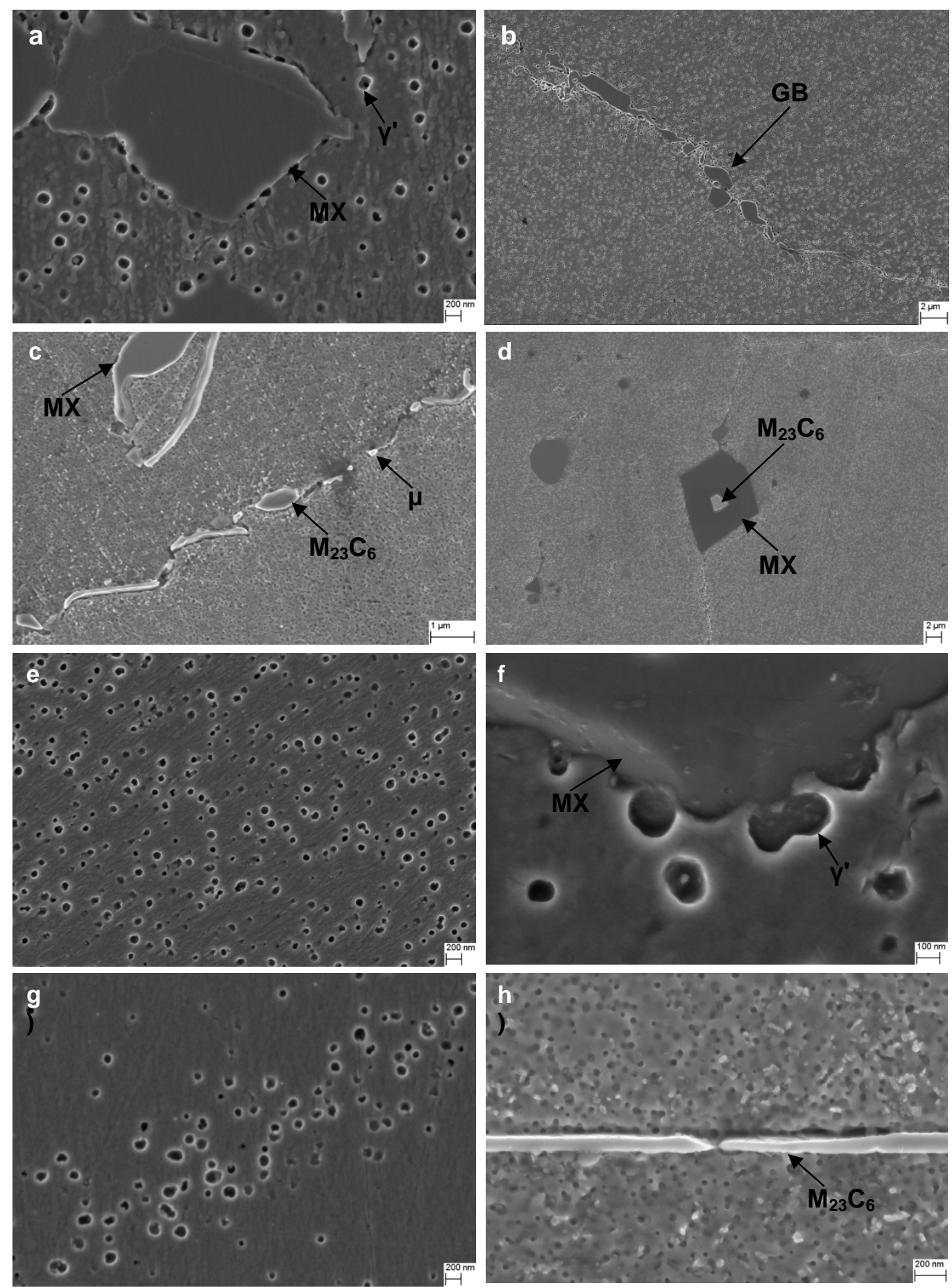
Figure 9: (a) high magnification SEM image of intragranular $M X$ precipitate and $\gamma$ ' impressions in sample 4; (b) SEM image of a mix of $M X, M_{6} C$ and $M_{23} C_{6}$ precipitates at $G B$; (c) $M_{23} C_{6}$ and $\mu$ phase at $G B$ and intragranular $M X$; (d) $M_{23} C_{6}$ nucleated on MX precipitate; (e) $\gamma^{\prime}$ impressions; (f) impressions of $\gamma^{\prime}$ particles nucleating on $M X$; $(g)$ r'alignment; (h) $M_{23} C_{6}$ decorating a twin boundary

Beside the precipitation of $\gamma^{\prime}$ a significant effect on mechanical properties is expected to be caused by the large amount of grain boundary precipitation. Precipitates decorate all grain and twin boundaries forming a semi-continuous film. The dominant species at $\mathrm{GBs}$ are $\mathrm{M}_{23} \mathrm{C}_{6}$; twins are exclusively decorated by $\mathrm{M}_{23} \mathrm{C}_{6}$. Although a limited precipitation of $\mathrm{M}_{23} \mathrm{C}_{6}$ phase at $\mathrm{GBs}$ usually prevents the grain boundaries from sliding, excessive coarsening and the eventual formation of a continuous film will have a negative effect on fracture toughness. Also, the corrosion resistance may be of concern since the carbides soak up $\mathrm{Cr}$, making it non- uniformly distributed in the microstructure and depleting the matrix adjacent to the GBs. Finally, a limited extent of $\gamma^{\prime}$ particle alignment has been observed in the samples crept at 700 and $750^{\circ} \mathrm{C}$, suggesting possible rafting initiation [23].

Phase quantification, particle size and inter-particle spacing analyses have been carried out on all the samples investigated using the procedures described in section 2.3. The results obtained for alloy IN617 are shown in Table 6. This activity provides several advantages: it helps quantifying the effects of thermomechanical treatments on the alloy (e.g. $\gamma$ ' precipitation and coarsening), and it provides data which can be used as input and validation for predictive models. 
Table 6: Phase fraction, average particle size and IPS for the IN617 specimens; "Other precipitates" include $M X, M_{23} C_{6}, M_{6} C$ and $\mu$; " $d$ " is the average size with spherical approximation; " $\mathrm{s}$ " is the average size with cubic approximation

\begin{tabular}{|c|c|c|c|c|c|c|c|c|c|}
\hline \multirow[t]{2}{*}{$\begin{array}{c}\text { IN617 } \\
\text { Specimen }\end{array}$} & \multirow{2}{*}{$\begin{array}{c}\gamma^{\prime} \text { Area } \\
\text { Fraction } \\
(\%)\end{array}$} & \multirow{2}{*}{$\begin{array}{c}\text { Other } \\
\text { Precipitates } \\
\text { Area } \\
\text { Fraction (\%) }\end{array}$} & \multicolumn{2}{|c|}{$\begin{array}{c}\gamma^{\prime} \text { Average } \\
\text { Size } \\
(\mathbf{n m})\end{array}$} & \multirow{2}{*}{$\begin{array}{c}\text { Other } \\
\text { Precipitate } \\
\text { s Average } \\
\text { Size } \\
(\mu \mathrm{m})\end{array}$} & \multirow{2}{*}{$\begin{array}{c}\text { GB } \\
\text { Precipitate } \\
\text { s Average } \\
\text { Size } \\
(\mu \mathrm{m})\end{array}$} & \multicolumn{2}{|c|}{$\begin{array}{c}\gamma^{6} \text { IPS } \\
(\mu \mathrm{m})\end{array}$} & \multirow{2}{*}{$\begin{array}{c}\text { GB } \\
\text { Particl } \\
\text { es IPS } \\
(\mu \mathrm{m})\end{array}$} \\
\hline & & & d & $\mathbf{s}$ & & & d & $\mathbf{s}$ & \\
\hline 1 & $9.4 \pm 1$ & $1.1 \pm 0.04$ & $\begin{array}{l}30 \\
\pm 4\end{array}$ & $\begin{array}{l}26 \\
\pm 3\end{array}$ & $0.73 \pm 0.05$ & $0.24 \pm 0.02$ & $\begin{array}{c}0.094 \\
\pm \\
0.01\end{array}$ & $\begin{array}{c}0.081 \\
\pm \\
0.01\end{array}$ & $\begin{array}{c}0.19 \\
\pm \\
0.01\end{array}$ \\
\hline 2 & $8 \pm 0.8$ & $0.61 \pm 0.02$ & $\begin{array}{l}80 \\
\pm 9\end{array}$ & $\begin{array}{l}71 \\
\pm 8\end{array}$ & $1.02 \pm 0.07$ & $0.53 \pm 0.04$ & $\begin{array}{c}0.22 \\
\pm \\
0.002\end{array}$ & $\begin{array}{c}0.2 \\
\pm \\
0.002\end{array}$ & $\begin{array}{c}0.089 \\
\pm \\
0.007\end{array}$ \\
\hline 3 & $6.4 \pm 0.7$ & $0.4 \pm 0.02$ & $\begin{array}{l}60 \\
\pm 7\end{array}$ & $\begin{array}{l}55 \\
\pm 6\end{array}$ & $0.61 \pm 0.04$ & $0.45 \pm 0.03$ & $\begin{array}{c}0.23 \\
\pm \\
0.003\end{array}$ & $\begin{array}{c}0.2 \\
\pm \\
0.002\end{array}$ & $\begin{array}{c}0.03 \\
\pm 0.002\end{array}$ \\
\hline 4 & $6 \pm 0.7$ & $1.53 \pm 0.04$ & $\begin{array}{r}120 \\
\pm 13\end{array}$ & $\begin{array}{r}110 \\
\pm 12\end{array}$ & $1.17 \pm 0.08$ & $0.87 \pm 0.06$ & $\begin{array}{c}0.49 \\
\pm \\
0.005\end{array}$ & $\begin{array}{c}0.43 \\
\pm \\
0.005\end{array}$ & $\begin{array}{c}0.094 \\
\pm \\
0.007 \\
\end{array}$ \\
\hline 5 & $8.4 \pm 0.9$ & $\mathrm{x}$ & $\begin{array}{l}55 \\
\pm 5\end{array}$ & $\begin{array}{r}48 \\
\pm 4\end{array}$ & $\mathrm{x}$ & $0.29 \pm 0.03$ & $\begin{array}{c}0.17 \\
\pm \\
0.01\end{array}$ & $\begin{array}{c}0.15 \\
\pm \\
0.01\end{array}$ & $\begin{array}{c}0.29 \\
\pm \\
0.02\end{array}$ \\
\hline
\end{tabular}

The gamma prime measurements, of particular interest in this study, reflect the trend predicted by modelling using MatCalc (see table 7):

Table 7: $\gamma^{\prime}$ phase fraction, predicted by means of MatCalc as a function of time and temperature

\begin{tabular}{|l|l|l|}
\hline \multicolumn{3}{|c|}{ Gamma Prime } \\
\hline $650^{\circ} \mathrm{C}$ & $25,000 \mathrm{~h}$ & $7.8 \%$ \\
\hline $700^{\circ} \mathrm{C}$ & $25,000 \mathrm{~h}$ & $7.1 \%$ \\
\hline $750^{\circ} \mathrm{C}$ & $25,000 \mathrm{~h}$ & $6.0 \%$ \\
\hline
\end{tabular}




\subsection{Continuum damage mechanics approach}

The modeling activity requires the input data obtained experimentally, which have been discussed in the previous sections. In particular, the parameters of interest in the present investigation are the type of phases present in each specimen, their volume fractions, particle size and inter- particle spacing (IPS), as a function of time, temperature and stress $[13,15]$.

\subsubsection{Model Details}

The strain rate during creep can be modeled using a set of material-based constants and four microstructural damage parameters. The approach follows the reasoning of Dyson [15], adapted more specifically for high alloy ferritic steels by Yin and Faulkner [13]. The four microstructural damage parameters are as follows: 1) $D_{d}$, a dislocation damage parameter based on the accumulation of a dislocation distribution occurring up until the end of primary creep; 2) $D_{s}$, a solute hardening parameter based on the changes in solute hardening caused by various matrix element partitioning effects occurring during the various precipitation sequences that takes place during exposure at high temperature; 3) $\mathrm{D}_{\mathrm{p}}$, a precipitation hardening parameter describing the hardening caused by precipitates during creep exposure at high temperature, which is essentially related to the inter-particle spacing where:

$\mathrm{D}_{\mathrm{P}}=1-\left(\mathrm{P}_{\mathrm{i}} / \mathrm{P}\right)$,

$\mathrm{P}_{\mathrm{i}}$ being the initial inter-particle spacing and $\mathrm{P}$ being the inter-particle spacing after time t; 4) $D_{n}$, a cavity density term describing the structural integrity of the material in the creep fracture crack path, which is usually the grain boundary.

These parameters are combined together in an equation for instantaneous creep rate, $\dot{\varepsilon}$, given as follows:

$$
\dot{\varepsilon}=\frac{\dot{\varepsilon}_{0}}{\left(1-\mathrm{D}_{\mathrm{d}}\right)\left(1-\mathrm{D}_{\mathrm{S}}\right)} \sinh \left[\frac{\sigma(1-\mathrm{H})}{\sigma_{0}\left(1-\mathrm{D}_{\mathrm{P}}\right)\left(1-\mathrm{D}_{\mathrm{N}}\right)}\right]
$$

$\dot{\varepsilon}_{0}$ is a temperature dependent constant defining the base level strain rate and $\sigma_{0}$ is a "composite" parameter containing several microstructural parameters [13]. $\sigma$ is the applied stress. The temperature dependence is given by: 
$\dot{\varepsilon}_{0}=\dot{\varepsilon}_{0}^{\prime} \exp \left(1-\frac{Q_{\mathrm{dj}}}{\mathrm{RT}}\right)$

where $\dot{\varepsilon}_{0}^{\prime}$ is a base line strain parameter, which is constant for steels and nickel base alloys, $Q_{d j}$ is an activation energy describing the combine activation energies for jog formation and diffusion in the material concerned, $\mathrm{R}$ is the gas constant and $\mathrm{T}$ is the absolute temperature.

The temperature dependence of $\sigma_{0}$ is given by:

$\sigma_{0}=\sigma_{0, \mathrm{~m}}\left\{1-\exp \left[-\frac{\Delta \mathrm{H}}{\mathrm{RT}_{\mathrm{s}}}\left(\frac{\mathrm{T}_{\mathrm{s}}}{\mathrm{T}}-1\right)\right]\right\}$

where $\sigma_{0, \mathrm{~m}}$ is a base-line stress constant, which is constant for steels and nickel base alloys, $\Delta \mathrm{H}$ is the enthalpy of solution for the alloy range being considered, $T_{S}$ is the absolute solvus temperature for the primary precipitate phase $\left(\gamma^{\prime}\right.$ in nickel base alloys), and $\mathrm{T}$ is the absolute temperature.

Parameters used in the above analysis are given in Table 7.

Table 7: Parameters used in CDM Calculations

\begin{tabular}{|c|c|}
\hline Parameter & Value \\
\hline$\dot{\varepsilon}_{0}\left({ }^{-1}\right)$ & 7400 \\
\hline $\mathrm{Q}_{\mathrm{dj}}\left(\mathrm{J} \mathrm{mol}^{-1}\right)$ & 300 \\
\hline$\sigma_{0, \mathrm{~m}}(\mathrm{MPa})$ & 33 \\
\hline$\Delta \mathrm{H} / \mathrm{RT}_{\mathrm{s}}$ & 0.35 \\
\hline $\mathrm{T}_{\mathrm{s}}(\mathrm{K})$ & 1350 \\
\hline
\end{tabular}

The most sensitive controlling parameter is $\mathrm{H}$ :

$\mathrm{H}=\frac{\sigma_{\mathrm{i}}}{\sigma}$

$\sigma i$ is defined as the internal back stress generated during stress redistribution within the 'hard' regions of the microstructure (particles and subgrains) as inelastic strain accumulates. $\sigma$ is the applied stress. The value of $1-\mathrm{H}$ has been used as a fitting parameter to achieve the correct levels of strain rate on which to build the appropriate effects of the damage parameters. 


\subsubsection{Application of the CDM model to alloy IN617}

We have applied the CDM approach to alloy 617. Our knowledge of the microstructural evolution on this alloy is based on experimental evidence presented in this paper and the knowledge of microstructural evolution in other nickel based alloys, like IN740 [14], Nimonic 80A [23] and high alloy ferritic steels, like P92 [13]. The general picture in nickel based alloys is that $\gamma^{\prime}$ forms at an early stage after ageing at $650-750^{\circ} \mathrm{C}$, accompanied by chromium-based carbides, like $\mathrm{M}_{23} \mathrm{C}_{6}, \mathrm{M}_{6} \mathrm{C}$ and, eventually, $\mathrm{M}_{7} \mathrm{C}_{3}$. There is some solution hardening element transfer to the growing carbides, but this is much more prevalent in the ferritic steels, like P92, and has been neglected for the case of the nickel alloys where the precipitation of $\gamma^{\prime}$ phase is predominant. This has led us to using a minimal solute hardening damage parameter, Ds, throughout our treatment of the CDM modelling of alloy 617. Subsequently, in the case of alloy 617 , in the ageing and service sequence the carbides partly transform gradually in-situ to $\mu$ phase. This type of phase is connected with encouraging grain boundary failure and therefore predominantly affects the cavity damage parameter, Dn, in the tertiary creep stage. Secondary creep is primarily controlled by slow evolution of the carbides and $\gamma^{\prime}$ phases through the process of coarsening. The mean inter-particle spacing increases with time. This parameter is inversely proportional to the strengthening effect of the particles, and so the precipitate evolution damage parameter, $\mathrm{Dp}$, increases with time. The influence on $\mathrm{Dp}$ of the other precipitates, whose volume fraction is significantly lower than that of $\gamma^{\prime}$, is negligible in comparison to that of $\gamma^{\prime}$. In particular, the IPS trend for species present especially at GBs is the opposite of that expected for IG particles growth, as shown in Table 6. This is inherent to the nature of growth and to the morphology of such particles at grain boundaries which tend to form a semicontinuous film.

We assume that primary creep damage is almost instantaneous, and the hardening produced by the initial dislocation distribution leads to a maximum hardening parameter, Dd, from the beginning of the creep process. In summary Dd (at a maximum) and Ds (at a minimum) are constant through the creep life simulation for alloy 617. The damage is primarily controlled by $\gamma^{\prime}$ particle coarsening based ramped Dp in secondary creep, and substantial increases in Dn in the later, tertiary stages of creep at $3 \%$ and $10 \%$ strain, caused by cavitation.

The strain at any instant in time, $t$, is therefore dependent on the particular combination of damage parameters for that time and strain, $t_{D p, D n, D d, D s}$. It is calculated from the following equation. 
$\varepsilon_{\mathrm{t} \text { Dp,Dn,Dd,Ds }}=\int_{0}^{\mathrm{t}_{\mathrm{DpDnDdDs}}} \dot{\varepsilon} \mathrm{dt}=\dot{\varepsilon} \mathrm{t}_{\text {Dp,Dn,Dd,Ds }}$

This method yields a slight over-estimate of the predicted strain, because it assumes that the damage parameters used have applied over the whole time involved. In fact, at shorter times, smaller damage parameters would have been in operation.

\subsubsection{Results and discussion for alloy IN617}

The predictions, based on the phase quantification data, have been performed and obtained for three temperatures: 750,850 and $950^{\circ} \mathrm{C}$. The choice of temperatures has been made so that the predictions could be compared with available experimental data. It is assumed that in this material at these temperatures and at stresses of 59,54 , and $46 \mathrm{MPa}$ respectively there is zero solute hardening. $1-\mathrm{H}$ is assumed to be $5 \times 10^{-16}$. $\mathrm{D}_{\mathrm{n}}$ is assumed to be 0.95 at strains above $3 \%$, and 0.99 above $10 \%$ strain.

At $750^{\circ} \mathrm{C} \mathrm{D}_{\mathrm{p}}=0.05$ because at this low temperature and short time of $100 \mathrm{~h}$, precipitate coarsening will not have taken place. $D_{n}$ and Ds $=0.05$ because there is no solute hardening as discussed above, and there is no tertiary stage for the times involved. For the relatively short times and low temperatures here, the primary damage accumulation will not have fully occurred, so $\mathrm{D}_{\mathrm{d}}=0.95$.

At $850^{\circ} \mathrm{C}, \mathrm{D}_{\mathrm{p}}$ is ramped from 0.05 to 0.5 from $100 \mathrm{~h}$ to $1000 \mathrm{~h}$, reflecting substantial coarsening gradually occurring over this time at the temperature concerned. $D_{n}$ and $D_{s}=0.05$ for the same reasons as discussed for $750^{\circ} \mathrm{C}$. Primary creep is complete after these times at higher temperatures than $750^{\circ} \mathrm{C}$ and so $\mathrm{D}_{\mathrm{d}}=0.99$

At $950^{\circ} \mathrm{C}$ the coarsening is complete after a few hours and so $D_{p}$ is $0.5 . D_{s}=0.05$ and $\mathrm{D}_{\mathrm{d}}=0.99$ for the same reasons as are discussed for $850^{\circ} \mathrm{C}$. The curve is in tertiary creep after 100 hours and so $D_{n}=0.05$ for $100 \mathrm{~h}$ and since the strain is between 3 and $10 \% D_{n}$ is 0.9 for $200 \mathrm{~h}$.

The results together with experimental measurements (VTT data) are given in Figure 10a. Chosen parameters are tabulated in Table 8.

Table 8: Damage Parameters used for Alloy 617 considering $1-H=5 \times 10^{-16}$

\begin{tabular}{|c|l|c|c|c|}
\hline $\begin{array}{c}\text { Temperature } \\
\left({ }^{\circ} \mathbf{C}\right)\end{array}$ & \multicolumn{1}{|c|}{$\mathbf{D}_{\mathbf{p}}$} & $\mathbf{D}_{\mathbf{n}}$ & $\mathbf{D}_{\mathbf{d}}$ & $\mathbf{D}_{\mathbf{s}}$ \\
\hline 750 & $\begin{array}{l}0.05(0.67 \text { for } 16000 \\
\text { hr) }\end{array}$ & 0.05 & 0.95 & 0.05 \\
\hline 850 & Ramped from 0.05 to & 0.05 & 0.99 & 0.05 \\
\hline
\end{tabular}




\begin{tabular}{|c|c|c|c|c|}
\hline & $\begin{array}{c}0.5 \text { from } 100 \text { to } 1000 \\
\text { hours }\end{array}$ & & \\
\hline 950 & 0.5 & $\begin{array}{c}0.05(100 \mathrm{~h}), 0.9 \\
(200 \mathrm{~h})(3 \%<\varepsilon \\
<10 \%)\end{array}$ & 0.99 & 0.05 \\
& & & \\
\hline
\end{tabular}

A link with microstructural data taken from this study (see Table 6) can be made for the $750^{\circ} \mathrm{C}$ material at $16000 \mathrm{~h}$. In this case the cavity, dislocation, and solute hardening parameters remain the same, but the inter-particle spacing is seen from the table to increase from around $150 \mathrm{~nm}$ (sample 5) to $450 \mathrm{~nm}$ (sample 4) for the $\gamma^{\prime}$ phase, which is assumed to be the major contributor to the damage. This allows us to conclude that $D_{p}$ increases to 0.67 after $16000 \mathrm{~h}$. If this parameter is included in the CDM calculation, then a predicted strain of $6.5 \%$ is forecast (see Fig 10b). The specimen from which the microstructural data was obtained was stressed at $68 \mathrm{MPa}$ and had not failed, but a glance at the stress rupture properties for Alloy 617 at $750^{\circ} \mathrm{C}$ shows failure to be expected at around 100000 $h$ at a stress of $72 \mathrm{MPa}$ (see Fig 10c). So it is not unreasonable to conclude that the material was just entering the tertiary creep regime at $16000 \mathrm{~h}$, thus justifying the choice of damage parameters. The use of stress used in the modelling (54 $\mathrm{MPa}$ ) compared to that applied to the specimen (68MPa) is not thought to influence the outcome significantly.

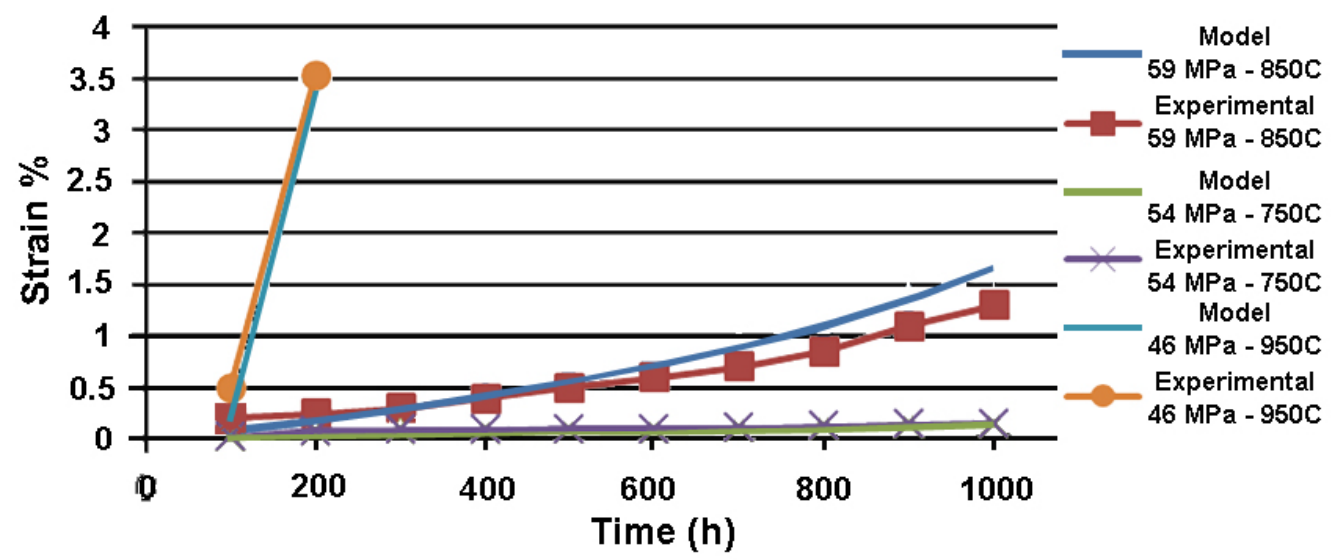

Figure 10a: Experimental (VTT data) and predicted creep curves for alloy 617 at 750,850 , and $950^{\circ} \mathrm{C}$, at 54, 59, and $46 \mathrm{MPa}$ respectively 


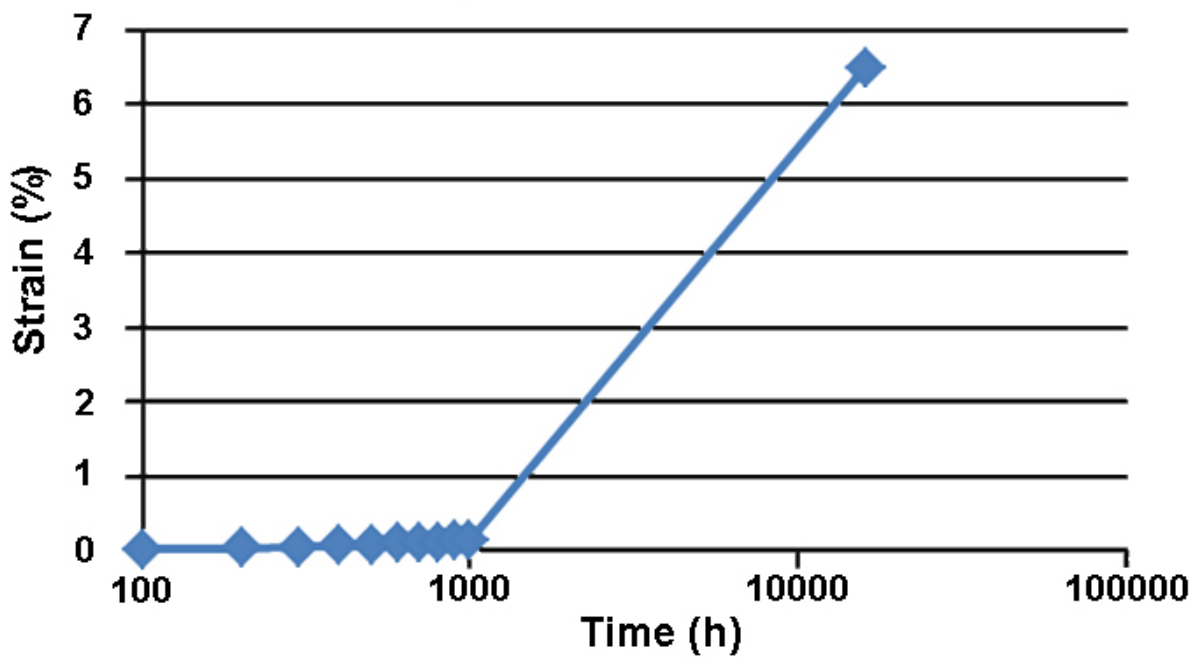

Figure 10b: Predicted creep curve for alloy 617 after $16000 \mathrm{~h}$ at $750^{\circ} \mathrm{C}$ using $D_{p}$ $=0.67$, based on experimental IPS data for $\gamma$ ' phase

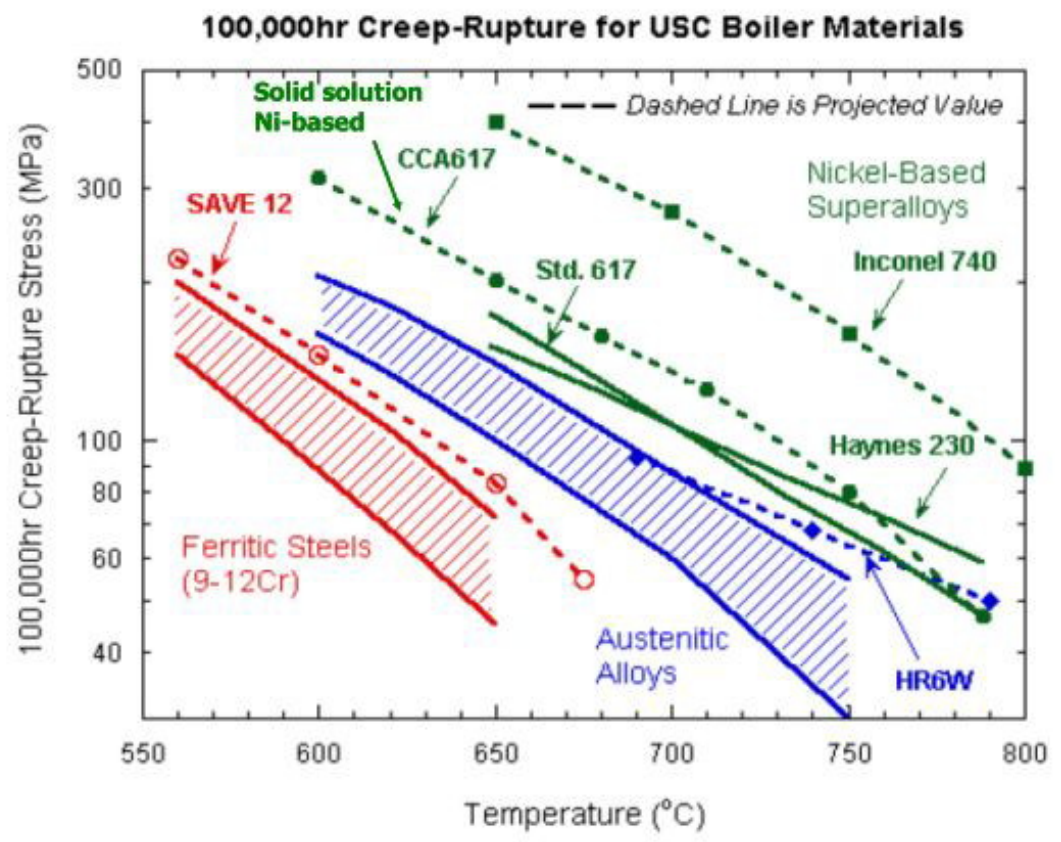

Figure 10c: 100000 h creep rupture curves for several USC boiler alloys, including alloy 617 [23]

\section{CONCLUSIONS}


The microstructures of as-received and crept IN617 samples have been characterised. The phases present have been identified and related to the microstructural evolution of the alloy. Phase quantification, particle size and inter-particle spacing analyses have been carried out on all specimens, thus providing accurate information about the microstructural evolution as a function of thermo-mechanical treatment. The data obtained have been used as input in a model forecasting the creep life of the alloys. The measured creep curves for alloy 617 agree well with predictions using a microstructural damage parameter based continuum damage mechanics approach and represent a promising base for further model development. The microstructural damage parameters used reflect the perceived microstructural state of the material at the various stages on the creep curve.

\section{REFERENCES}

[1] R. Viswanathan, W. Bakker. "Materials for Ultrasupercritical Coal Power Plants-Boiler Materials", Part 1. Journal of Materials Engineering and Performance, Vol. 10 (2001), pp. 81-95

[2] T. B. Gibbons. "Superalloys in modern power generation applications", Materials Science and Technology, Vol. 25 (2009), pp. 129-135

[3] A. Sharma, B. J. P. Buhre, S. Richardson, C. Spero, T. Wall. "Fired Supercritical Boilers Operational Issues and Coal Quality Impacts”, Technical Note 20. CCSD(Cooperative Research Centre for Coal in Sustainable Development) Report, 2002.

[4] R. Viswanathan et al. "U.S. Program on Materials Technology for UltraSupercritical Coal Power Plants", Journal of Materials Engineering and Performance Vol. 14 (2005), pp. 281-292

[5] R. C. Reed. “The Superalloy Fundamentals and Applications” (Cambridge University Press, 2006)

[6] J. P. Shingledecker, R. W. Swindeman, Q. Wu, V. K. Vasudevan. "Creep Strength of High Temperature Alloys For Ultra-supercritical Steam Boilers", 4th EPRI Conference on Advances in Materials Technology for Fossil Power Plants, 2007 
[7] M. J. Donachie, S. J. Donachie. "SUPERALLOYS: A Technical Guide”, (ASM International: 2002)

[8] I. A. Shibli, S. R. Holdsworth. "Creep and Fracture in High Temperature Components: Design and Life Assessment Issues”, (DEStech Publications, Inc.: 2009)

[9] M. Cabibbo M, E. Gariboldi, S. Spigarelli, D. Ripamonti. "Creep behavior of INCOLOY Alloy 617”, Journal of Material Science, Vol 43 (2008), pp. 2912-21

[10] E. Gariboldi, M. Cabibbo, S. Spigarelli, D. Ripamonti. "Investigation on precipitation phenomena of Ni-22Cr-12Co-9Mo alloy aged and crept at high temperature", International Journal of Pressure Vessels and Piping, Vol. 85 (2008), 63-71

[11] Q. Wu, H. Song, R. W. Swindeman, J. P. Shingledecker, V. K. Vasudevan. "Microstructure of Long-Term Aged IN617 Ni-Base Superalloy", Metallurgical and Materials Transactions A, Vol. 39 (2008), pp. 2569-2585

[12] D. E. Clark, J.A. Simpson, T. C. Totemeier, H. Tian. Microstructure And Strength Characteristics of Alloy 617 Welds, INL (2005)

[13] Y. F. Yin, R. G. Faulkner. "Continuum damage mechanics modelling based on simulation of microstructural evolution kinetics”, Materials Science and Technology, Vol. 22, n. 8 (2006), pp.929-936

[14] S. F. Di Martino, R. G. Faulkner, S. C. Hogg. "Characterisation of Microstructure and Creep Properties of Alloy IN740 for Ultra-Supercritical Power Plants”, Materials Science and Technology (2014)

[15] B. Dyson. "Use of CDM in marerials modelling and component creep life prediction”, Journal of Pressure Vessel Technology, Vol. 122 (2000), pp. 281296

[16] A. K. Roy, M. H. Hasan, J. Pal. "Creep deformation of Alloys 617 and 276 at 750-950 ${ }^{\circ}$ ”, Materials Science and Engineering A”, Vol. 520 (2009), pp. $184-188$

[17] H. S. Hosseini, M. Shamanian, A. Kermanupar. "Characterization of microstructures and mechanical properties of Inconel 617/310 stainless steel dissimilar welds”, Materials Characterization, Vol. 62 (2011), pp. 425-431

[18] S. Rahman, G. Priyadarshan, K. S. Raja, C. Nesbitt, M. Misra. "Characterization of high temperature deformation behaviour of INCONEL 617”, Mechanics of Materials, Vol. 41 (2009), pp. 261-270 
[19] S. Chomette, J.-M. Gentzbittel, B. Viguier, "Creep behaviour of as received, aged and cold worked INCONEL 617 at $850^{\circ} \mathrm{C}$ and $950^{\circ} \mathrm{C}$ ”, Journal of Nuclear Materials, Vol. 339 (2010), pp. 266-274

[20] W. L. Mankins, J. C. Hosier, T. H. Bassford. "Microstructure and phase staibility of INCONEL alloy 617”, Metallurgical Transactions, Vol. 5 (1974), pp. 2579-2590

[21] A.-G. Mohammad, M. Mehdizadeh. "Effect of long-term service exposure on microstructure and mechanical properties of alloy 617”, Materials and Design, Vol. 32 (2011), pp. 2695-2700

[22] http://www.msm.cam.ac.uk/phase-trans/2003/Superalloys/rafting.html [23] W.E. Voice, R.G. Faulkner. "Carbide stability in Nimonic 80A alloy", Metallurgical and Materials Transactions A, Vol. 16 (1985), pp.511-520

[24] http://amse.skku.edu/html/research_pop_ceramic.php?idx=3

\section{Acknowledgements}

The investigation is part of the collaborative project ENER/FP7EN/249809/MACPLUS, funded by the EU within the FP7 framework. Special thanks to O. Tassa (C.S.M.) and C. Davis (E.On) for providing the heat treated materials. 